\title{
In vivo Infusion of NGF Induces the Organotypic Regrowth of Perivascular Nerves following Their Atrophy in Aged Rats
}

\author{
Timothy J. Andrews ${ }^{\mathrm{a}}$ and Timothy Cowen \\ Department of Anatomy and Developmental Biology, Royal Free Hospital School of Medicine, London NW3 2PF, United \\ Kingdom
}

The aim of this study was to investigate whether NGF could reverse the nerve fiber atrophy exhibited by some neurons in old age. We used quantitative immunohistochemical techniques to investigate how the autonomic nerves that supply different blood vessels are affected by aging. Age changes in the nerve plexus were not widespread but were specific to particular vascular targets. Furthermore, where nerve fiber atrophy did occur, it affected different populations of nerves; specifically, sympathetic nerve fibers were lost from the middle cerebral artery while nonsympathetic nerves were lost from the tail vein. Peripheral target tissues have been shown to have a trophic influence on the pattern and density of their innervation, which declines in old age (Gavazzi et al., 1992), possibly as a result of decreased availability of neurotrophic factors such as NGF. Consequently, in an attempt to reverse nerve fiber atrophy, we used miniosmotic pumps to infuse NGF for 2 weeks over involuting nerve flbers in the middle cerebral artery of freely moving aged rats. Our results show that exogenous NGF can induce organotypic neurite outgrowth from aged neurons undergoing nerve fiber atrophy. Moreover, NGF can induce a change in the pattern of the old nerve plexus to one similar to that seen in young animals. NGF had different effects on the extent and manner of neurite outgrowth in young and aged nerves. NGF induced greater nerve growth in old compared to young nerves, causing old nerves to grow within existing nerve bundles and to sprout new nerve fibers, in contrast to young nerves, which tended to grow only within existing nerve bundles. In conclusion, this study shows the potential of exogenous NGF to reverse age-related changes in neuronal morphology.

[Key words: NGF, aging, atrophy, plasticity, peripheral nerve, autonomic nerves, neurodegeneration, sympathetic nerves, cerebral blood vessels]

The heterogeneous appearance of neuronal atrophy is a prominent feature of the aged nervous system. Age-related neuronal changes in the PNS (Giacobini, 1988; Cowen, 1993a) and CNS

\footnotetext{
Received May 24, 1993; revised Sept. 10, 1993; accepted Nov. 1, 1993.

We are particularly grateful to Chris Thrasivoulou for his expert technical assistance and to Isabella Gavazci for her helpful criticism of the manuscript. The research was supported by grants from the Wellcome Trust, Royal Society, and the British Heart Foundation. T.A. was supported by a junior research fellowship from the Royal Free Hospital School of Medicine.

Correspondence should be addressed to Tim Cowen, Ph.D., Department of Anatomy and Developmental Biology, Royal Free Hospital School of Medicine, Rowland Hill Street, London, NW3 2PF, UJK

Present address: Department of Neurobiology, Duke University, Durham, NC. Copyright (C) 1994 Society for Neuroscience $0270-6474 / 94 / 143048-11 \$ 05.00 / 0$
}

(Wright et al., 1991; Selkoe, 1992) show both spatial and temporal specificity. A fundamental question in studies of aging is whether neuronal atrophy is primarily a result of intrinsic changes in the neuron or a result of changes in its external environment (Cowen, 1993b; Finch, 1993). A recent study using transplantation has shown that age-related nerve fiber atrophy in the PNS can be caused by a loss of trophic support from peripheral target tissues (Gavazzi et al., 1992). The role of extrinsic factors in neuronal aging has received further support from studies showing that aged peripheral neurons are not impaired in their capacity for neurite outgrowth (Crutcher, 1990; Suhonen et al., 1991; Gavazzi and Cowen, 1993a). Decreased availability of target-derived NGF has been proposed as a factor in age-related neurodegenerative diseases (Appel, 1981; Bartus et al., 1982; Perez-Polo et al., 1990). However, a proven relationship between levels of NGF in target tissues and neuronal atrophy has yet to be established.

Target tissues influence the phenotype and survival of their innervating neurons via the production of neurotrophic factors (Levi-Montalcini, 1987; Purves, 1988). NGF is the best characterized neurotrophic factor (Bjerre et al., 1975; Yankner and Shooter, 1982; Thoenen, 1991), the role of which was first established in sympathetic and sensory neurons (Levi-Montalcini and Hamburger, 1951; Levi-Montalcini and Booker, 1960) and later in CNS neurons (Seiler and Schwab, 1984). NGF treatment in vivo can induce nerve growth from young and adult neurons (Snider, 1988; Isaacson et al., 1990; Ruit and Snider, 1991; Zettler et al., 1991). However, it is not known whether NGF can induce nerve growth from aged neurons in vivo. In vitro studies provide conflicting evidence. Some studies show that NGF is able to elicit neurite outgrowth from aged sympathetic and sensory neurons but to a lesser extent than that seen in young neurons (Uchida and Tomonaga, 1985a,b; Hellweg et al., 1990), while others show that neurite outgrowth of aged sensory neurons is unaffected by NGF (Fukuda et al., 1991).

In this study we aimed first to identify where nerve fiber atrophy occurs during aging and second, to investigate whether exogenous NGF can reverse this fiber atrophy. The perivascular nerve plexus can contain both sympathetic and sensory neurons, which depend on NGF for trophic support. Vascular smooth muscle, which is a target of these nerves, has been shown to produce NGF (Crecdon and Tuttle, 1991). Wc hypothesize that age-related fiber atrophy seen in these perivascular nerves can be caused by loss of neurotrophic support provided by their targets. Histochemical and immunohistochemical markers for neuroactive substances have been widely used to study agerelated or experimentally induced changes in neuronal morphology (Dhall et al., 1986; Mione et al., 1988). However, be- 
cause neurotransmitter expression can be affected by old age (Kedzierski and Porter, 1990) or experimental manipulations such as NGF infusion (Thoenen et al., 1971; Lindsay et al., 1989), there is a risk of confusing changes in the levels of neuroactive substances with nerve growth or atrophy. Antibodies to PGP9.5, a general neuronal marker, may help to overcome this problem (Gulbenkian et al., 1987; Wilson et al., 1988). A previous study using PGP9.5 showed that the nerve plexuses of the posterior cerebral artery exhibit atrophy combined with reduced levels of transmitter (Cowen and Thrasivoulou, 1990). Furthermore, PGP9.5 has been shown to record accurately agerelated atrophy in the innervation of human skin (Abdel-Rahman et al., 1992). In the present study, noradrenaline histochemistry was used to detect age changes in perivascular sympathetic nerves (Todd, 1980; Cowen et al., 1982). Established methods of image analysis were employed to quantify nerve density (Cowen et al., 1986; Cowen and Thrasivoulou, 1992). We used miniosmotic pumps to infuse exogenous NGF over the peripheral nerve plexuses around the cerebral arteries of freely moving young and old rats. Our results suggest that NGF can induce neurite outgrowth from perivascular nerves undergoing age-related atrophy.

\section{Materials and Methods}

Sprague-Dawley rats were killed at 6 weeks, 7 months, 18 months, and 24 months of age. Six weeks represents an age when the animals are sexually mature and the perivascular nerve plexus established. At 7 months the animals had achieved maximum body length and were fully mature but not aged; 18 and 24 months represent two different stages of the aging process. At 24 months the animals were senile, mortality ranging from $30 \%$ to $50 \%$ of the population. The innervation of five blood vessels, the middle cerebral and basilar arteries, the superior vena cava, and the portal and tail veins, was studied using indirect immunohistochemistry for the gencral ncuronal marker PGP9.5 and glyoxylic acid histochemistry (Lindvall and Bjorklund, 1974) to demonstrate noradrenergic nerves. Animals were given an overdose of pentobarbitone sodium $(500 \mathrm{mg} / \mathrm{kg})$ and perfused through the heart with Tyrode's solution before tissue was taken for histochemical and immunohistochemical processing.

$N G F$ infusion. Following the demonstration of nerve fiber atrophy in the nerve plexuses of the middle cerebral artery, these nerves were treated with exogenous NGF. Rats were used at 6 weeks and 24 months of age to compare the effects of NGF on young and aged nerves. Under deep halothane anesthesia, rats were fixed in a stereotaxic head frame. A sagittal scalp incision was made along the midline. The scalp and the temporal muscle on the left side were retracted laterally. A bone window was drilled below the sagittal suture and between the coronal and lambdoid sutures. The middle cerebral artery was identified and the dura over the artery incised. A catheter connected to a miniosmotic pump (Charles Riner Ltd., UK; pump 2002) was inserted subdurally next to the artery so that it could perfuse NGF over the nerves on the adventitial surface of the vessel. The pump was sutured subcutaneously between the scapulae, the incision closed and the rats allowed to recover. Neither old nor young animals displayed any infection or other problems following the operation. Animals fed and behaved normally. Two hundred microliters of NGF (100 $\mathrm{\mu g} / \mathrm{ml}$; Boehringer, UK) or vehicle containing cytochrome C (cyt $\mathrm{C} ; 100 \mu \mathrm{g} / \mathrm{ml}$; Calbiochem, UK) were infused for 14 $\mathrm{d}$ in freely moving rats. NGF and cytochrome $\mathrm{C}$ were dissolved in PBS containing 1\% rat albumin (Sigma). At the end of the experiment, animals were killed with an overdose of pentobarbitone sodium $(500 \mathrm{mg} /$ $\mathrm{kg}$ ) and perfused through the heart with Tyrode's solution followed by 4\% paraformaldehyde in PIPES buffer. Cerebral arteries were removed and processed for PGP9.5 immunohistochemistry.

PGP immunohistochemistry. PGP9.5 immunohistochemistry was used to detect all nerve groups of the perivascular nerve plexus. Vessels were removed quickly and immersed in $4 \%$ paraformaldehyde for $2 \mathrm{hr}$. An eyepiece graticule was used in the dissecting microscope to stretch the vessels to their in vivo dimensions before pinning onto silicone rubber strips and fixation. All vessels except the basilar and middle cerebral arteries were opened and pinned adventitial side up. Vessels were washed in PBS and treated with $0.1 \%$ Triton X-100 and $80 \%$ alcohol to enhance penetration of antibodies. Conventional immunohistochemical procedures were used to process the specimens; $5 \%$ swine serum in PBS was applied for $2 \mathrm{hr}$ followed by anti-PGP9.5 (Ultraclone, UK) diluted 1:400, overnight, and a fluorescein isothiocyanate (FITC)-conjugated swinc anti-rabbit IgG (Dako) diluted 1:80, for $2 \mathrm{hr}$. Antibodies were diluted in PBS containing 1\% swine serum, $0.1 \%$ sodium azide, and $0.1 \%$ Triton. Vessels were counterstained with $0.05 \%$ pontamine sky blue (BDH, UK) (Cowen et al., 1985) for $10 \mathrm{~min}$, restretched to their in vivo dimensions over mica strips, and mounted in an antifade mountant (Citifluor, UK).

Noradrenaline histochemistry. Cerebral arteries were removed and quickly stretched to in vivo dimensions on Sylgard, while larger vessels were opened and pinned adventitial side up. Specimens were incubated in a $2 \%$ glyoxylic acid solution in phosphate buffer $(\mathrm{pH} 7.2)$ at room temperature for $90 \mathrm{~min}$. For the last $10 \mathrm{~min} 0.05 \%$ pontamine sky blue was added to the incubation solution. The vessels were then stretched on mica, placed in a chamber at $80 \%$ humidity for $15 \mathrm{~min}$ and then in an oven at $80^{\circ} \mathrm{C}$ for $5 \mathrm{~min}$, and finally mounted on microscope slides in liquid paraffin.

Light microscopical image analysis. Specimens were observed with an Olympus Vanox AH-2 fluorescence microscope. Three fields were chosen from the rostral, middle, and caudal ends of each vessel and nerve fiber density was quantified using established methods of image analysis (Cowen and Burnstock, 1982; Cowen and Thrasivoulou, 1992). A Kontron IPS image analyzer was interfaced to the microscope via a low-light video camera (model VL350, PCO Computer Optics GmbH Germany). An image of the nerve plexus was taken into the image analyzer. The gain setting and integration time of the camera were set so that the maximum intensity of the images to be analyzed did not exceed the maximum gray value of 255 . Images were subject to background subtraction and standard image enhancement and thresholding routines. The resulting binary image of the nerve plexus was measured automatically using established parameters.

Expression of nerve density. Two parameters of nerve density, percentage of area (area\%) and intercept density (ID), were measured on all vessels. Area\% represents the percentage of the vessel surface covered by nerves. Changes in area\% can be due to an increase in number of nerve bundles, an increase in the size of nerve bundles, or a combination of the two. ID measures the number of nerve bundles, irrespective of size, which intercept a grid placed at right angles to the vessel axis and is expressed as ID per millimeter. The fraction area\%/intercept density gives a figure proportional to the average size of nerve bundles. Statistical comparisons between nerve densities were made using one-way ANOVA.

\section{Results}

Target-specific nerve fiber atrophy of sympathetic and nonsympathetic nerves in old age

The pattern of PGP-immunoreactive (-IR) nerve plexuses on the cerebral arteries showed changes with age (Fig. 1). Younger vessels had both large, longitudinally orientated, "paravascular" nerve bundles located in the superficial adventitia and fine, randomly orientated, "pcrivascular" nerve fibers located at the adventitial-medial border. In contrast, older vessels had predominately fine, perivascular nerve fibers forming a relatively random plexus. The PGP-IR nerve plexus of the tail vein was less dense than the cerebral arteries described above but was more dense than the other two veins. It had both peri- and paravascular components (Fig. 2). The nerve plexuses to the portal vein and the superior vena cava had similar patterns of innervation consisting of relatively sparse, randomly orientated, thick and fine nerve bundles.

Different patterns of nerve plexus were obtained with noradrenaline histochemistry. Whereas PGP-IR nerve bundles were both thick and fine, noradrenergic nerve bundles were mostly fine (Fig. 3), demonstrating the high level of noradrenaline present in the smaller, terminal nerves. PGP, on the other hand, detects all nerves including the large nerve bundles carrying 

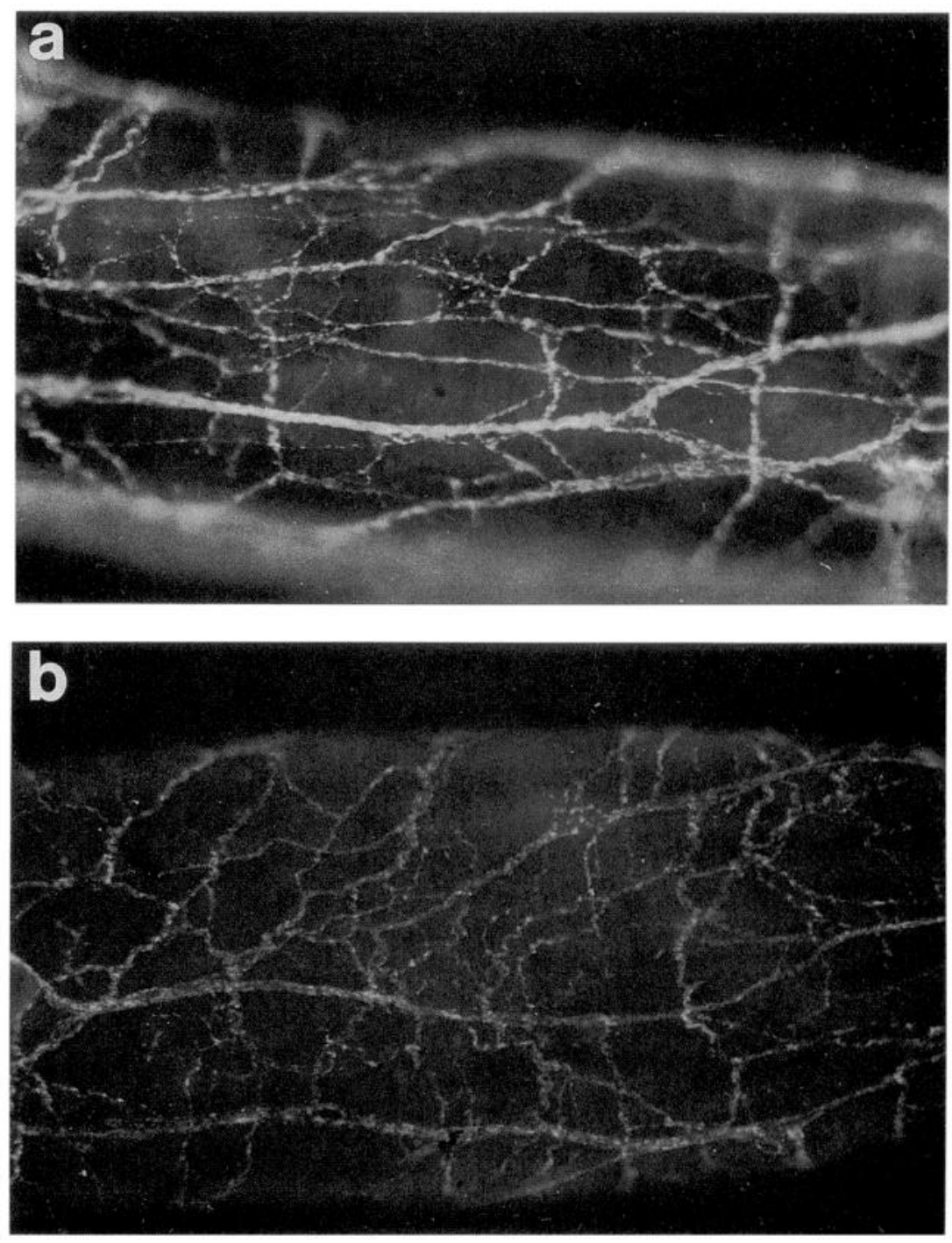

Figure 1. Photomicrographs showing the total nerve plexus of the middle cerebral artery through development and aging. Nerve bundles were visualized using indirect immunohistochemistry with the general neuronal marker PGP9.5. and a secondary antibody conjugated with FITC. In old age the nerve plexus becomes visibly less dense and contains few large nerve bundles. The axis of the vessel runs from right to left. The nerve plexus was investigated at 6 weeks $(a), 7$ months $(b)$, and 24 months of age (c). Scale bar, $50 \mu \mathrm{m}$.

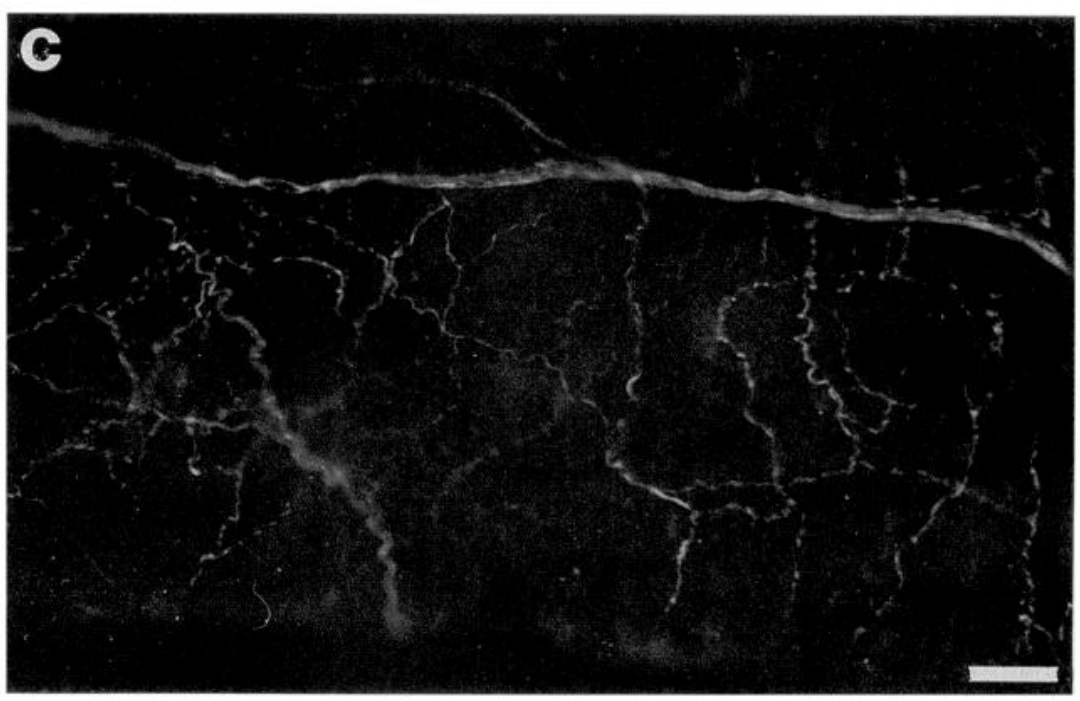

fibers of transit to other areas of the blood vessel and nonsympathetic nerve fibers. The density of the noradrenergic innervation was similar to that obtained by PGP, suggesting that sympathetic nerves are the most profuse in the perivascular plexus (Todd, 1980; Mione et al., 1988). However, comparisons of nerve densities visualized with different staining techniques are unreliable because of differing levels of contrast and stain intensity (Webster et al., 1991). In whole-mount preparations 

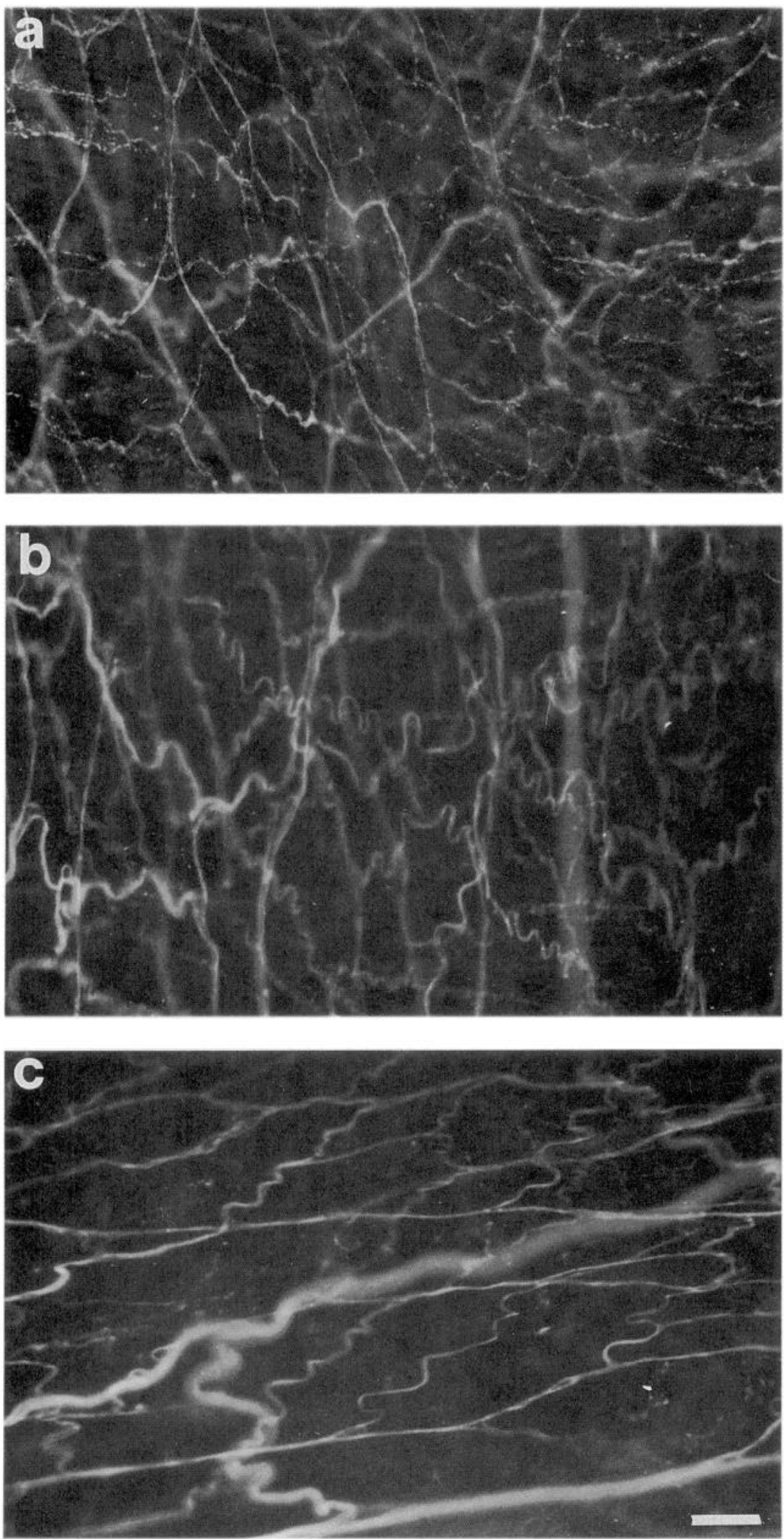

Figure 2. Photomicrographs showing the total nerve plexus of the tail vein through development and aging. Nerve bundles were visualized using indirect immunohistochemistry with the general neuronal marker PGP9.5. and a secondary antibody conjugated with FITC. Two types of nerve bundles can be identified: large, superficial "paravascular" nerves and smaller, "perivascular" nerves. In old age the nerve plexus becomes visibly less dense. The axis of the vessel runs from top to bottom in $a$ and $b$ and from right to left in $c$. Nerve plexuses were investigated at 6 weeks $(a), 7$ months $(b)$, and 24 months of age $(c)$. Scale bar, $50 \mu \mathrm{m}$. of the portal vein, immunohistochemistry using PGP9.5 only detected the superficial nerve plexus, in contrast to noradrenaline histochemistry, where both the superficial and intramuscular nerve plexus were detected.

Because the size of blood vessels changed with age, we at- tempted to evaluate changes in the total nerve population supplying a segment of the vessel wall. The circumference of each vessel was measured and multiplied by its PGP-IR nerve ID to give a number representing the total ID.

We showed that significant age-related nerve fiber atrophy 

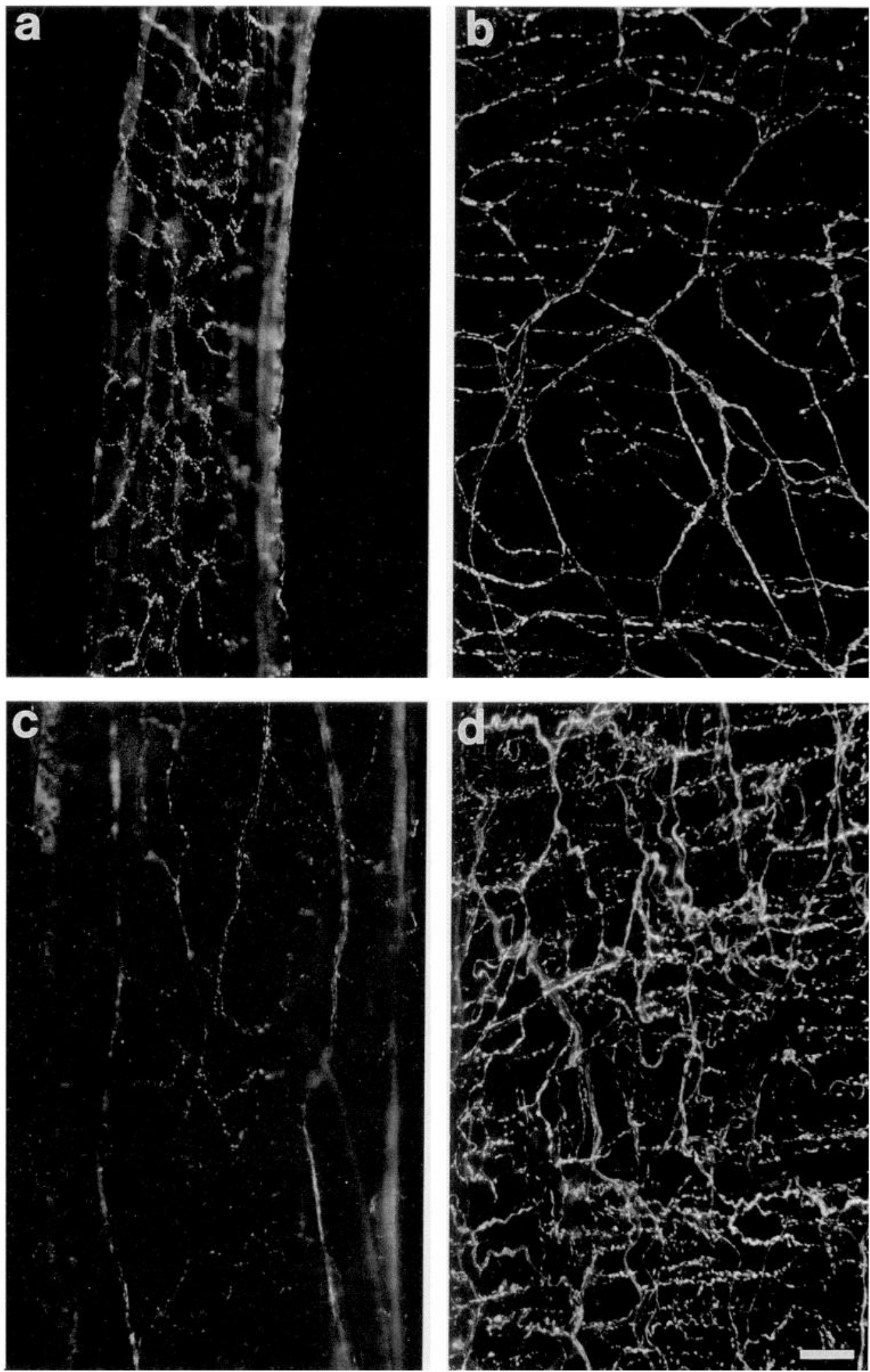

Figure 3. Photomicrographs showing the sympathetic innervation of the middle cerebral artery and the tail vein through development and aging. Sympathetic nerves were identified using noradrenaline histochemistry on the middle cerebral artery $(a, c)$ and the tail vein $(b, d)$. Nerve plexuses were investigated at 6 weeks $(a, b)$ and 24 months $(c, d)$ of age. Note that the relatively thick nerve bundles are less prominent with noradrenaline histochemistry. The axis of the vessels runs from top to bottom. There is a visible decrease in the nerve density of the middle cerebral artery with age in contrast to the increased nerve density of the tail vein. Scale bar, $50 \mu \mathrm{m}$.

occurred in the middle cerebral artery and tail vein. In the middle cerebral artery there was a $50 \%$ decrease in the density of PGP-IR nerves (Fig. 4) ( $p<0.001$ ), which gives a $40 \%$ decrease in the total ID after compensation for age-related growth in vessel size (Table 1) $(p<0.01)$. The sympathetic innervation of the middle cerebral artery also decreased by about $50 \%$ (Fig. 5) $(p<0.001)$ in old age, indicating that the nerve fiber atrophy seen in the "total" innervation of the middle cerebral artery is primarily due to loss of sympathetic fibers from the nerve plexus.

In the tail vein, the density of PGP-IR nerve plexuses decreased by about $50 \%$ in old age (Fig. 4) $(p<0.001)$, which translated to a $40 \%$ loss of the total ID (Table 1) $(p<0.01)$. However, there was a $50 \%$ increase in the density of the sympathetic innervation of the tail vein over the same period (Fig. 


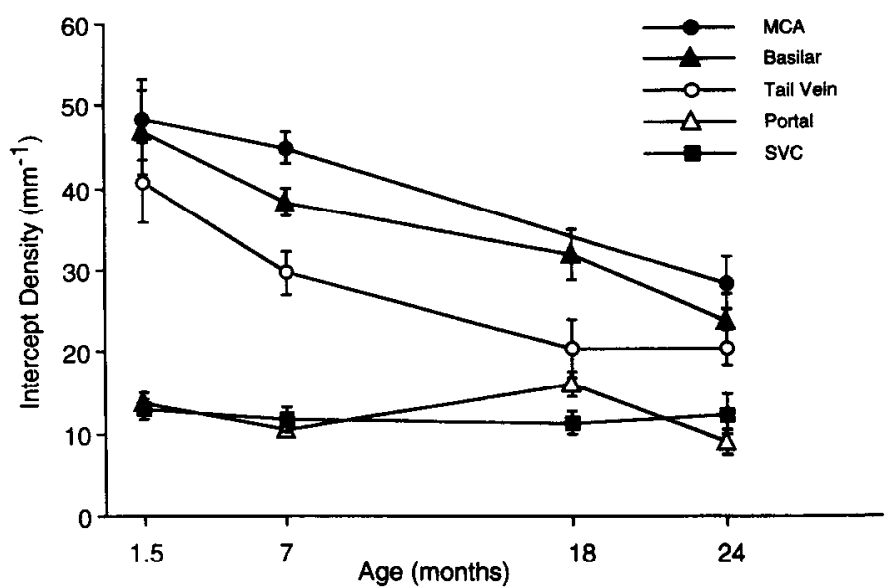

Figure 4. Graph showing the density of peripheral nerves supplying different blood vessels through development and aging. Nerves were detected using indirect immunohistochemistry with the general neuronal marker PGP9.5. Images of the nerve plexus were quantified using image analysis. ID represents the number of nerve bundles that innervate a grid placed a right angles to the vessels axis and is expressed as intercepts per millimeter. There was a significant decrease in the density of the middle cerebral artery $(p<0.001)$, the basilar artery $(p<0.001)$, and the tail vein $(p<0.001)$ with age ( 1.5 vs 24 months) but no change in the portal vein or superior vena cava. Error bars show SEM; $n=8$ for all groups. $M C A$, middle cerebral artery; Basilar, basilar artery; Portal, portal vein; $S V C$, superior vena cava.

$5, p<0.001)$. This implies that fiber atrophy in the PGP-IR nerve plexus is due to loss of nonsympathetic nerves that are presumably sensory or parasympathetic. No evidence of PGPIR or noradrenergic nerve fiber loss was seen on the superior vena cava.

\section{NGF treatment on young and aged perivascular nerves}

In order to avoid confusing changes in neuroactive substances with nerve fiber growth and atrophy, we have used PGP9.5 exclusively for the evaluation of nerve density in NGF treated nerve fibers. We did not observe any obvious changes in the stain intensity of PGP-IR nerves with age or following NGF treatment.

NGF treatment for 2 weeks induced a change in the pattern of innervation in old cerebral arteries as demonstrated by PGPIR (Fig. 6). The typical PGP-IR nerve plexus on aged cerebral blood vessels is comprised of a sparse, randomly orientated network of fine nerve bundles (see Fig. 1c). Following treatment with NGF, the aged nerve plexus develops large, longitudinally

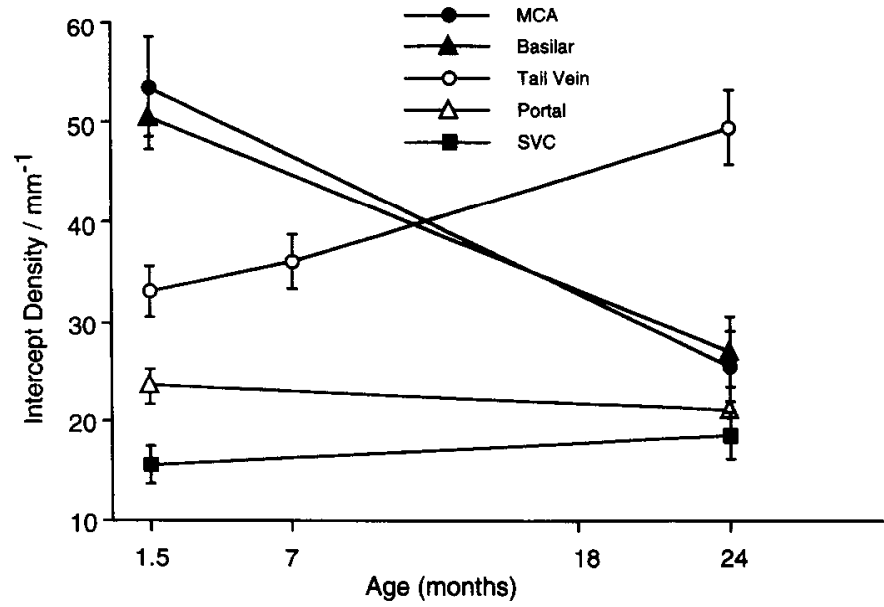

Figure 5. Graph showing the density of sympathetic nerves supplying different blood vessels through development and aging. Sympathetic nerves were detected using noradrenaline histochemistry. Images of the nerve plexus were quantified using image analysis. ID represents the number of nerve bundles that innervate a grid placed a right angles to the vessels axis and is expressed as intercepts per millimeter. There was a significant decrease in the sympathetic nerve density on the middle cerebral artery $(p<0.001)$ and the basilar artery $(p<0.001)$ but an increase on the tail vein $(p<0.005)$ with age ( $1.5 \mathrm{vs} 24$ months). There was no change in the innervation density of the portal vein or superior vena cava. Error bars show SEM; $n=8$ for all groups. $M C A$, middle cerebral artery; Basilar, basilar artery; Portal, portal vein; $S V C$, superior vena cava.

arranged nerve bundles overlying a network of fine, dense, randomly orientated nerves resembling the pattern seen on young vessels.

The effect of NGF on the density of perivascular nerves from young and aged cerebral blood vessels is summarized in Figure 7. In the old middle cerebral artery, NGF increased the area $\%$ of PGP-IR nerves relative to untreated vessels $(205 \%, p<0.001)$ and cyt $\mathrm{C}$ vehicle-treated controls $(p<0.05)$. Furthermore, NGF caused a significant increase in the ID of PGP-IR nerves on old middle cerebral artery relative to untreated $(85 \%, p<$ $0.005)$ and cyt $C$ vehicle-treated controls $(p<0.05)$. Because the increase in the area $\%$ of PGP-IR nerves was larger than the increase in the ID we can infer (see Expression of nerve density, in Materials and Methods) that NGF increased both the size and number of nerve bundles. Interestingly, cyt $\mathrm{C}$ vehicle caused a significant increase in area $\%(116 \%, p<0.01)$ but not ID of PGP-IR nerves on the old middle cerebral artery, suggesting

Table 1. Nerve fiber density and circumference of blood vessels through development and ageing

\begin{tabular}{|c|c|c|c|c|c|c|c|c|}
\hline & \multicolumn{2}{|c|}{ Young (6 week) } & \multicolumn{2}{|c|}{ Adult ( 7 month) } & \multicolumn{2}{|c|}{ Aged (18 month) } & \multicolumn{2}{|c|}{ Senile ( 24 month) } \\
\hline & $\begin{array}{l}\text { Circum- } \\
\text { ference } \\
(\mathrm{mm})\end{array}$ & Total ID & $\begin{array}{l}\text { Circum- } \\
\text { ference } \\
(\mathrm{mm})\end{array}$ & Total ID & $\begin{array}{l}\text { Circum- } \\
\text { ference } \\
(\mathrm{mm})\end{array}$ & Total ID & $\begin{array}{l}\text { Circum- } \\
\text { ference } \\
(\mathrm{mm})\end{array}$ & Total ID \\
\hline $\mathrm{MCA}$ & $0.29 \pm 0.01$ & $14.1 \pm 1.4$ & $0.4 \pm 0.02^{* *}$ & $18.0 \pm 1.2$ & ND & ND & $0.39 \pm 0.02$ & $11.4 \pm 1.6^{* *}$ \\
\hline $\mathrm{BA}$ & $0.34 \pm 0.02$ & $17.1 \pm 2.3$ & $0.5 \pm 0.04^{* *}$ & $19.3 \pm 1.5$ & $0.49 \pm 0.03$ & $17.3 \pm 2.6$ & $0.60 \pm 0.04$ & $14.1 \pm 1.5$ \\
\hline TV & $0.67 \pm 0.03$ & $29.7 \pm 2.6$ & $1.3 \pm 0.13^{* *}$ & $39.7 \pm 4.1^{*}$ & $1.19 \pm 0.16$ & $24.4 \pm 5.8^{* *}$ & $1.16 \pm 0.09$ & $23.2 \pm 2.6$ \\
\hline PV & $4.70 \pm 0.46$ & $68.5 \pm 7.0$ & $6.4 \pm 0.27^{* *}$ & $66.3 \pm 3.7$ & $5.68 \pm 0.29$ & $89.4 \pm 11.4$ & $5.73 \pm 0.50$ & $59.6 \pm 9.5^{*}$ \\
\hline SVC & $3.24 \pm 0.31$ & $47.0 \pm 3.6$ & $5.5 \pm 0.25^{* *}$ & $62.8 \pm 7.7$ & $4.94 \pm 0.45$ & $59.9 \pm 9.3$ & $6.03 \pm 0.03$ & $73.8 \pm 15$ \\
\hline
\end{tabular}

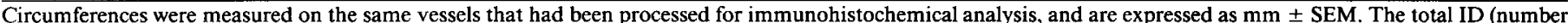

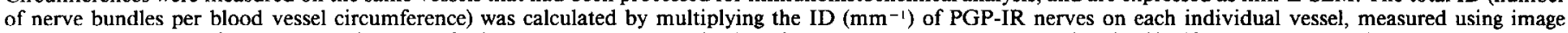

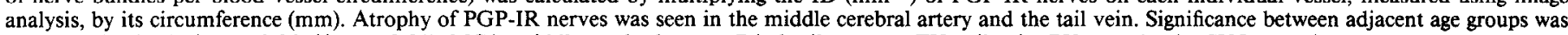
tested by ANOVA $\left({ }^{*}, p<0.05 ;{ }^{* *}, p<0.01\right)$. MCA, middle cerebral artery; BA, basilar artery; TV, tail vein; PV, portal vein; SVC, superior vena cava. 

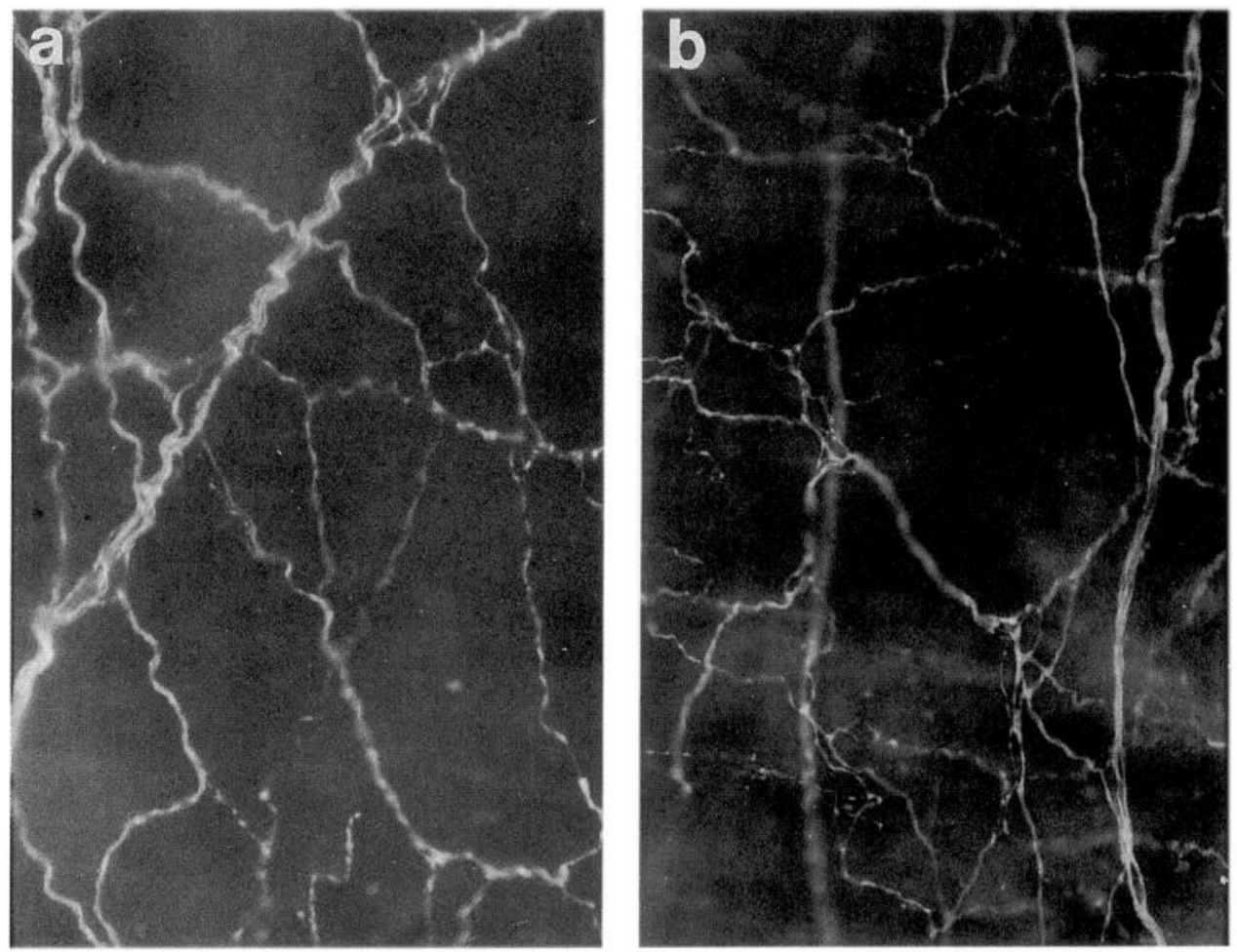

Figure 6. Photomicrographs showing the nerve plexus of the middle cerebral artery following treatment with cyt $\mathrm{C}$ and NGF. NGF $(c, d)$ and cyt $\mathrm{C}(a, b)$ was infused over the nerve plexus of the middle cerebral artery in 6 week (young) $(a, c)$ and 24 month (aged) $(b$, d) rats for 2 weeks. Nerve bundles were visualized using indirect immunohistochemistry with the general neuronal marker PGP9.5. and a secondary antibody conjugated to FITC. NGF induced aged neurons to regrow with a pattern of innervation resembling that seen in young animals. Image analysis was used to analyze the density of innervation. The axis of the vessels runs from top to bottom. Scale bar, $50 \mu \mathrm{m}$.
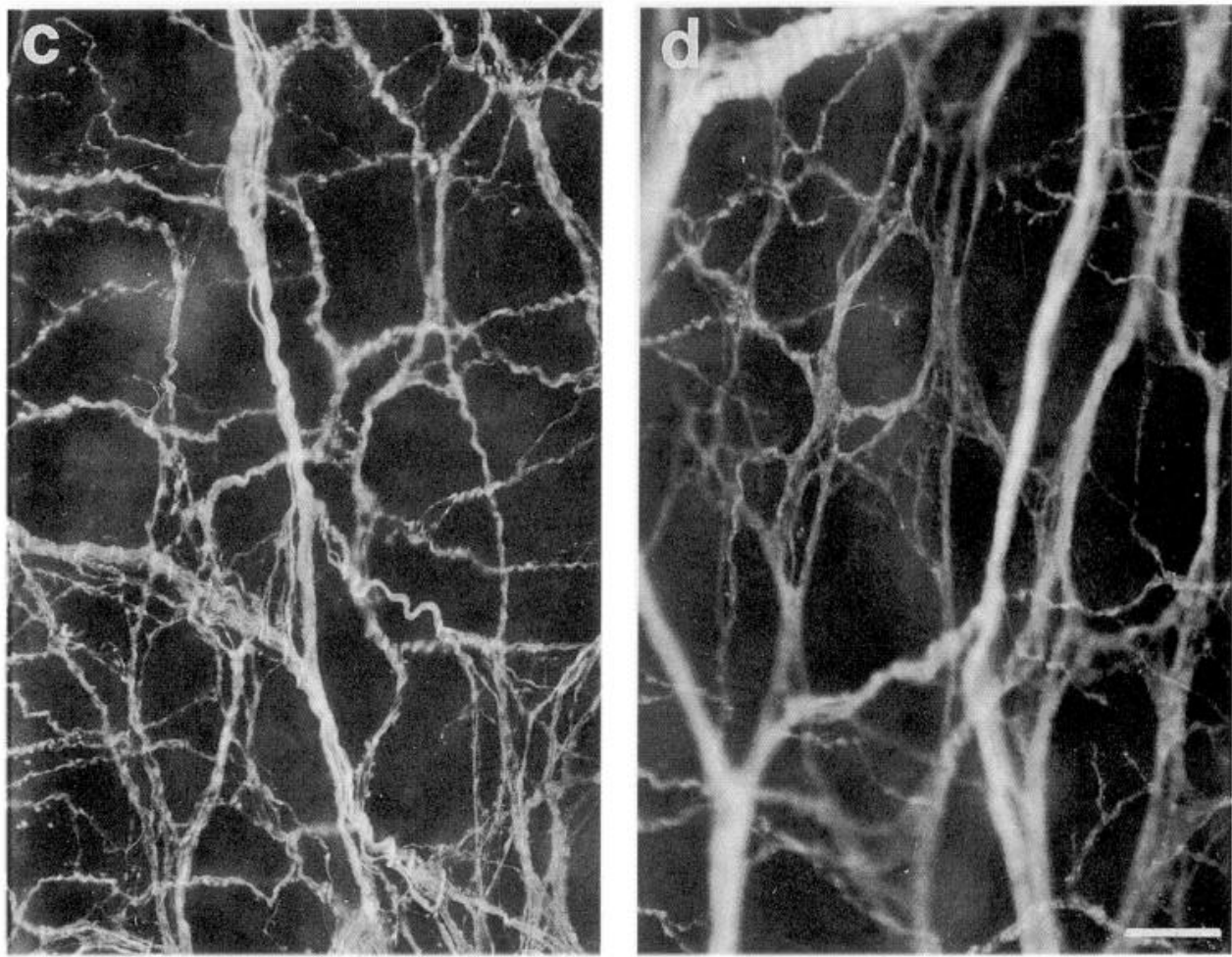

that vehicle-induced nerve growth was restricted to an enlargement of existing nerve bundles.

In the young middle cerebral artery, NGF increased the area\% of PGP-IR nerves relative to untreated $(74 \%, p<0.005)$ and cyt C-treated $(p<0.05)$ vessels. However, the ID was not affected. This implies that NGF infusion caused an increase in the size, but not the number, of nerve bundles on the young middle cerebral artery. Cyt $\mathrm{C}$ vehicle had no significant effect on the PGP-IR nerve density.
A previous study has shown that the vascular nerve plexus of the posterior cerebral artery, like the middle cerebral artery, also displays age-related nerve fiber atrophy (Cowen and Thrasivoulou, 1990). In the old posterior cerebral artery NGF induced a significant increase in the area\% (52\%) and ID (77\%) of PGP-IR nerves relative to untreated $(p<0.001)$ and cyt C vehicle-treated $(p<0.001)$ vessels. NGF increased the ID more than the area $\%$, inferring that the increase in nerve density is due to an increase in new nerve bundles and not to increased 
a
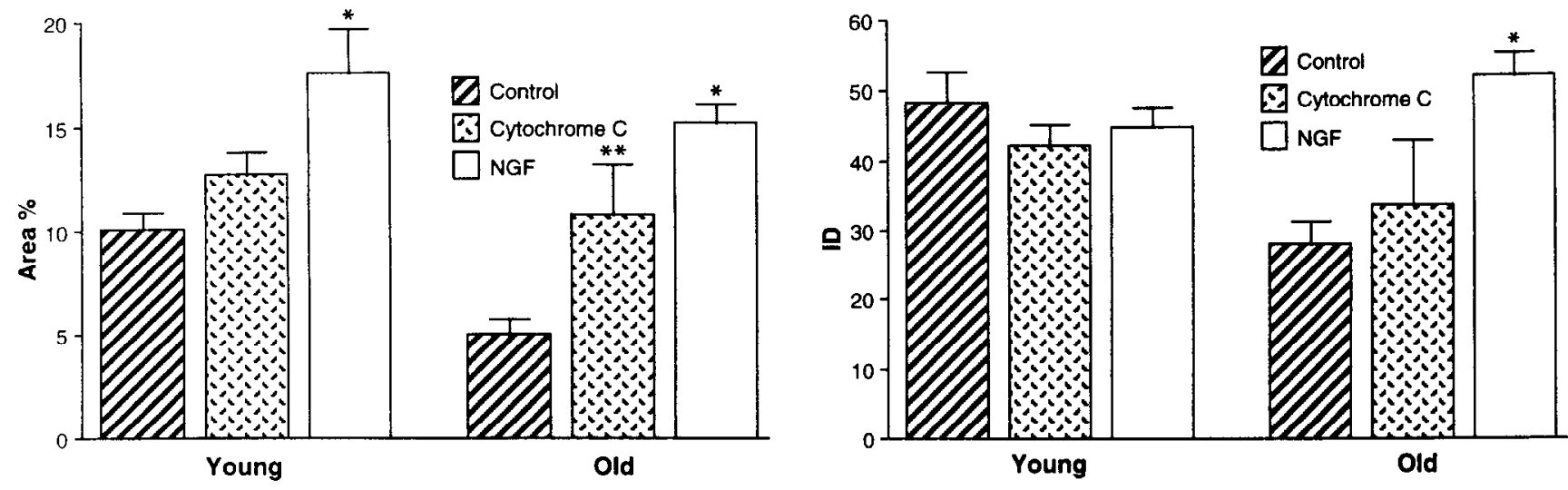

b
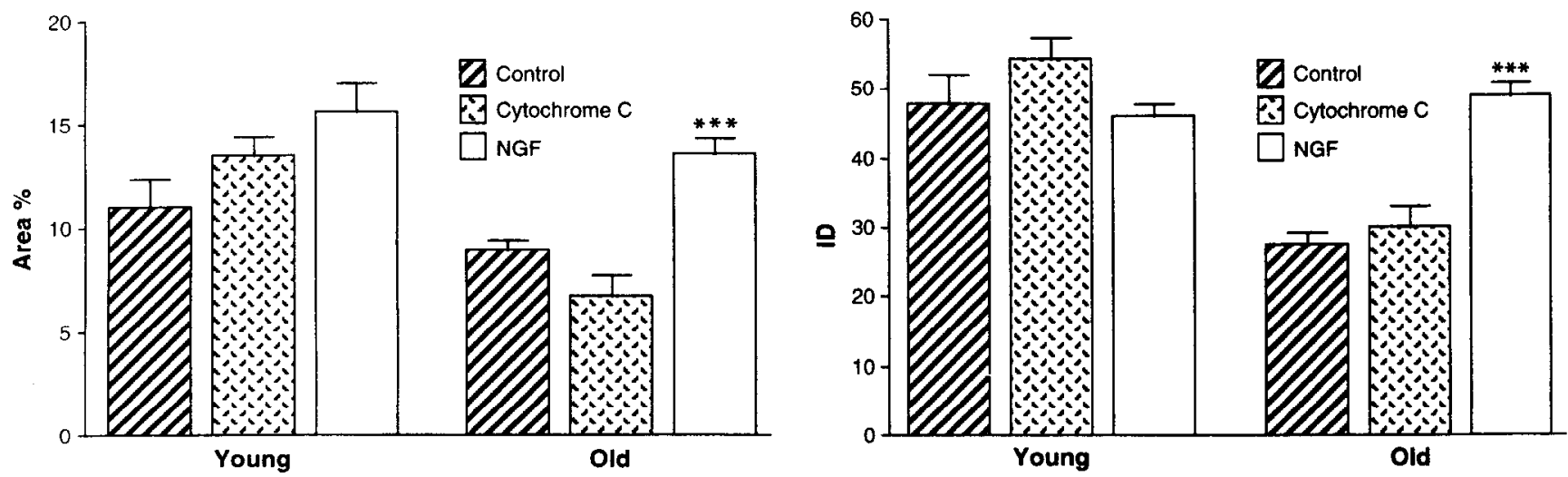

Figure 7. Histograms showing the effect of NGF on the nerve density of the middle $(a)$ and posterior cerebral artery $(b)$. NGF or cyt C was infused over the nerve plexus of the middle cerebral artery for 2 weeks in young ( 6 week) and aged ( 24 months) rats. Nerves were detected using indirect immunohistochemistry with the general neuronal marker PGP9.5. Images of the nerve plexus were quantified using image analysis. Control represents the untreated vessels. Area\% is the proportion of blood vessel wall covered by nerves, irrespective of their number. Intercept density $(I D)$ represents the number of nerve bundles that intersect a grid placed at right angles to the vessels axis and is expressed as intercepts per millimeter. $a$, In the middle cerebral artery NGF induced an increase in the number $(I D)$ and size (Area\%) of nerve bundles on old arteries but only induced an increase in the size $(A r e a \%)$ of nerve bundles young arteries. $b$, In the posterior cerebral artery NGF induces an increase in the $A r e a \%$ and $I D$ of the old nerve plexus. Error bars show SEM. In a (middle cerebral artery), for Young data, Control, $n=8 ;$ Cytochrome C, $n=5 ; N G F, n=4$; for Old data, Control, $n=8 ;$ Cytochrome $C, n=5 ; N G F, n=6$. In $b$ (posterior cerebral artery), for Young data, Control, $n=6 ; C y t o c h r o m e C, n=4 ; N G F, n$ $=4$; for Old data, Control, $n=6$; Cytochrome $C, n=5 ; N G F, n=6$. Significance between adjacent groups was tested using ANOVA $\left(^{*}, p<0.05\right.$; $\left.* *, p<0.01 ;{ }^{* * *}, p<0.001\right)$.

size of existing nerve bundles. Cyt $\mathrm{C}$ vehicle had no effect on nerve density.

In the young posterior cerebral artery, NGF induced a significant increase in the area\% of PGP-IR nerves relative to untreated $(41 \%, p<0.05)$ but not to cyt $\mathrm{C}$-treated vessels. ID of PGP-IR nerves was not affected. Cyt $\mathrm{C}$ vehicle had no effect on the PGP-IR nerve density. Therefore, in both the young middle and posterior cerebral arteries, NGF caused an increase in nerve bundle size but not in number. The increases in nerve density seen on the posterior cerebral artery following NGF treatment were less than on the middle cerebral artery, probably because of the greater distance of the posterior cerebral artery from the site of infusion.

\section{Discussion}

In an attempt to reverse the nerve fiber atrophy exhibited by some neurons in old age, we have infused NGF in vivo over their peripheral nerve fibers in old freely moving rats. The results described here demonstrate that the exogenous application of NGF in vivo to an aged nerve plexus can induce growth and regeneration of a pattern of innervation that resembles that seen in young animals. 


\section{Target-specific nature of nerve fiber atrophy}

The elucidation of the primary causative factors involved in neuronal atrophy is of fundamental importance in aging research. Rather than being a general phenomenon, neuronal atrophy is a temporally and spatially specific feature of the aged nervous system (Cotman and Holets, 1985; Giacobini, 1988; Selkoe, 1992). Furthermore, age changes in phenotypically similar neurons are species specific (Finch, 1993). The peripheral innervation of the vasculature provides a model system for studying neuronal atrophy with detailed descriptions of agerelated changes demonstrating spatial, temporal and species specificity (Cowen et al., 1982; Dhall et al., 1986; Mione et al., 1988; for review, see Cowen, 1993b). The vascular nerve plexus contains sympathetic, sensory, and parasympathetic nerves. Nerve fiber loss combined with reduced neurotransmitter content in residual fibers has been previously demonstrated in the postcrior cerebral artery (Cowen and Thrasivoulou, 1990). In this study we show that although nerve fiber loss was seen on the middle cerebral artery and tail vein, it was not universal Furthermore, while nerve fiber loss in the middle cerebral artery was caused primarily by the atrophy of sympathetic nerve fibers, in the tail vein the number of sympathetic nerves increased in old age while the overall (PGP-IR) innervation declined, suggesting a substantial loss of sensory and/or parasympathetic nerves. The hypertrophy of the sympathetic innervation on the tail vein in old age reveals the continued plasticity of aging neurons and corroborates other studies showing that age changes are not always degenerative (Buell and Coleman, 1979). These opening results reinforce the concept of heterogeneity in neuronal age changes.

Recent studies using in oculo transplantation have shown that age-related loss of some peripheral nerve fibers including those supplying cerebral blood vessels is primarily the result of changes in their non-neuronal peripheral target (Gavazzi et al., 1992). Further experiments have indicated retained plasticity of the aging neurons that innervate these targets (Crutcher, 1990; Suhonen et al., 1991; Gavazzi and Cowen, 1993a), strengthening the idea that changes in target tissues induce neuronal atrophy. We hypothesize that the region-specific changes in neuronal morphology that we and others have described in peripheral nerves is a result of decreased availability of target-derived factors such as NGF.

\section{$N G F$ and neuronal aging}

The role of target-derived NGF in the survival and development of neurons is well established (for review, see Bjerre et al., 1975; Levi-Montalcini, 1987; Yankner and Shooter, 1982; Thoenen, 1991). Levels of NGF in target tissues have been shown to correlate well with the density of their innervation (Korsching and Thoenen, 1983; Shelton and Reichardt, 1984). Central and peripheral neurons continue to require NGF for their survival and maintenance in old age (Montero and Hefti, 1989; Ruit et al., 1990; Sofroniew et al., 1990). However, to our knowledge, NGF treatment has not been used in vivo on specific populations of neurons where fiber atrophy has been characterized and quantitatively defined. We show that following NGF treatment the aged nerve plexus regenerates large longitudinally orientated nerve bundles as well as additional perivascular fibers, that is, a pattern and density resembling that seen on young blood vessels. This observation demonstrates the ability of NGF to induce organotypic neurite outgrowth from aged neurons in vivo. Fur- ther evidence for the ability of NGF to restore organotypic patterns of reinnervation comes from a recent study looking at the reinnervation of transplanted old cerebral blood vessels in oculo (Gavazzi and Cowen, 1993b). However, although the pattern of nerve growth that we observed in NGF-treated old cerebral arteries resembled that seen in young tissues, we do not know if the nerve growth was phenotypically appropriate; that is, wcre sympathetic nerves stimulated to regrow more than sensory nerves? However, a recent study has shown that NGFinduced sprouting of nerves on young-adult cerebral blood vessels is largely prevented by sympathectomy (Issacson et al., 1992). There is increasing evidence to show that cerebral blood vessels can be innervated by neurons of central origin. The cholinergic neurons of the basal forebrain have been shown to innervate the vasculature of the neocortex and hippocampus (Sato and Sato, 1992). Interestingly, these neurons have been shown to be dependent on NGF for their development and survival (Montero and Hefti, 1989; Sofroniew et al., 1990) and may also sprout in response to NGF infusion.

A decrease in the availability of neurotrophic factors has been linked with changes that take place in neurodegenerative diseases and normal aging (Bartus et al., 1982; Varon et al., 1988; Perez-Polo et al., 1990). NGF has been linked with the neurodegenerative changes that take place in the NGF-sensitive neurons of the basal forebrain during Alzheimer's disease (Appel, 1981). However, a clear connection between decreased NGF levels and neuronal atrophy remains to be established. A major problem has been the conflicting evidence for age-related changes in NGF in specified areas of the nervous system such as the aged neocortex, where there is evidence of decreased (Larkfors et al., 1987; Alberch et al., 1991) and unchanged (Goedert et al., 1986; Hellweg et al., 1990) levels of NGF and NGF mRNA. The discovery of a high-affinity NGF receptor (NGFr), the protooncogene trk (Hempstead et al., 1991; Klein et al., 1991), has led to speculation that NGFr and not NGF may be the important factor in neuronal aging (Hefti and Mash, 1989). A loss of NGFr has been reported in sympathetic ganglia from aged mice (Uchida and Tomonaga, 1987). NGF levels have been shown to regulate the expression of NGFr (Miller et al., 1991; Holtzman et al., 1992), and a decrease in NGF levels could explain the loss of NGFr seen in that study. However, NGF levels have not been studied in peripheral tissues of aging rats, and we cannot conclude from our results that a decrease in NGF availability causes the nerve fiber atrophy we have observed. Nonetheless, the ability of exogenous NGF to reverse age-related neurodegenerative changes with organotypic patterns of nerve regrowth provides circumstantial evidence for its role in vivo. However, we do not rule out that other aspects of the target may be involved such as extracellular matrix (Sanes, 1989) or neurotrophic factors other than NGF (Thoenen, 1991).

\section{The effect of NGF on young versus old neurons}

NGF had different effects on neurite outgrowth from old and young neurons. NGF induced more outgrowth from aged neurons, despite their ongoing fiber atrophy, compared to young nerves, suggesting that old nerves retain a substantial capacity for regrowth. This result contrasts with in vitro studies that show reduced neurite growth of aged sympathetic and sensory neurons in response to NGF (Uchida and Tomonaga, 1985a; Tanaka et al., 1990). However, in vivo studies have shown that the capacity of sympathetic neurons for neurite outgrowth is unaffected by age (Crutcher, 1990; Gavazzi and Cowen, 1993a). The expla- 
nation for the discrepancies between in vitro and in vivo studies may lie in the in vitro demonstration that the ability of NGF to elicit neurite outgrowth from young and aged sympathetic neurons depends on the substratum the neurons are grown on (Uchida and Tomonaga, 1985b), suggesting that trophic factors and extracellular matrix act synergistically in peripheral nerve growth.

Young and aged neurons responded differently to NGF in their manner of neurite outgrowth. NGF increased both the size and number of nerve bundles from aged animals but only increased the size of nerve bundles from young animals. Thus, neurite outgrowth from old neurons occurs along new as well as existing pathways, whereas nerve growth from young neurons occurs principally along existing pathways. Growing axons interact with growth-promoting components of the extracellular matrix such as laminin, via cell surface receptors such as integrins and with other axons and schwann cells via cell adhesion molecules. NGF is known to influence the expression of cell surface receptor molecules (Rossino et al., 1990). It is possible that NGF upregulates receptor molecules on old nerves favoring both fasciculation and sprouting, whereas it only upregulates receptors concerned with fasciculation in young nerves.

\section{Vehicle infusion induces nerve growth}

Cyt $\mathrm{C}$-containing vehicle solutions have been used in studies of NGF as a control with no neurogenic effects (Isaacson et al., 1990; Ruit et al., 1990; Saffran and Crutcher, 1990). However, in this study, an increase in nerve density was seen in the vehicleinfused, aged middle cerebral artery, albeit less than that produced by NGF. A recent investigation in our laboratory has shown that exogenous bovine serum albumin but not rat serum albumin induces increased nerve outgrowth from rat autonomic neurons (Gavazzi and Cowen, 1993b). This leads us to suggest that an immune or inflammatory reaction, induced or potentiated by the invasive surgery, could directly or indirectly generate nerve growth. Possible mechanisms could include the upregulation of NGF synthesis in fibroblasts by cytokines produced by invading cells of the immune system (Yoshida and Gage, 1992).

In conclusion, we have demonstrated the region-specific nature of nerve fiber atrophy as it effects the perivascular nerves of peripheral neurons, and have shown that different subpopulations of nerve fibers degenerate in different tissues. We have gone on to show that NGF can induce organotypic regrowth of degenerating nerves in aged rats. It has been suggested that NGF could be used as a therapeutic agent in human neurodegenerative diseases (Tuszynski et al., 1991). This study shows the potential of exogenous NGF to reverse age-related deficits in neuronal morphology. However, as yet we do not know whether the pattern of NGF-induced nerve regrowth is phenotypically appropriate or functional.

\section{References}

Abdel-Rahman TA, Collins KJ, Cowen T, Rustin M (1992) Immunohistochemical, morphological and functional changes in the peripheral sudomotor neuro-effector system in elderly people. J Auton Nerv Syst 37:187-198.

Alberch J, Pereznavarro E, Arenas E, Marsal J (1991) Involvement of nerve growth factor and its receptor in the regulation of the cholinergic function in aged rats. J Neurochem 57:1483-1487.

Appcl SH (1981) A unifying hypothesis for the cause of amyotrophic lateral sclerosis, parkinsonism, and Alzheimer disease. Ann Neurol 10:499-505.
Bartus RT, Dean RL, Beer B, Lippa AS (1982) The cholinergic hypothesis of geriatric memory dysfunction. Science 217:408-416.

Bjerre B, Wiklund L, Edwards DC (1975) A study of the de- and regenerative changes in the sympathetic ncrvous system of the adult mouse after treatment with the antiserum to nerve growth factor. Brain Res 92:257-278.

Buell SJ, Coleman PD (1979) Dendritic growth in the aged human brain and failure of growth in senile dementia. Science 206:854-856.

Cotman CW, Holets VR (1985) Structural changes at synapses with age: plasticity and regeneration. In: Handbook of the biology of ageing, Vol 2 (Finch CE, Schneider EL, eds), pp 617-644. New York: Van Nostrand Reinhold.

Cowen T (1993a) Regulation of the autonomic innervation of blood vessels during development and ageing. In: Vascular innervation and receptor mechanisms: new perspectives, pp 25-40. New York: Academic.

Cowen T (1993b) Ageing in the autonomic nervous system: a result of nerve target interactions? Mcch Agcing Dev 68:163-173.

Cowen T, Burnstock G (1982) Image analysis of catecholamine fluorescence. Brain Res Bull 9:81-86.

Cowen T, Thrasivoulou C (1990) Cerebrovascular nerves in old rats show reduced accumulation of 5-hydroxytryptamine and loss of nerve fibres. Brain Res 513:237-243.

Cowen T, Thrasivoulou C (1992) A microscopical assay using a densitometric application of image analysis to quantify neurotransmitter dynamics. J Neurosci Methods 45:107-116.

Cowen T, Haven AJ, Wen Qin C, Gallen DD, Franc F, Burnstock G (1982) Development and ageing of perivascular adrenergic nerves in the rabbit. A quantitative fluorescence histochemical study using image analysis. J Auton Nerv Syst 5:317-336.

Cowen T, Haven AJ, Burnstock G (1985) Pontamine sky blue: a counterstain for background autofluorescence in fluorescence and immunofluorescence histochemistry. Histochemistry 82:205-208.

Cowen T, Alafaci C, Crockard HA, Burnstock G (1986) 5-HT-containing nerves to major cerebral arteries of the gerbil originate in the superior cervical ganglion. Brain Res 384:51-59.

Creedon D, Tuttle JB (1991) Nerve growth factor synthesis in vascular smooth muscle. Hypertension 18:730-741.

Crutcher KA (1990) Age-related decrease in sympathetic sprouting is primarily due to decreased target receptivity: implications for understanding brain function. Neurobiol Aging 11:175-183.

Dhall U, Cowen T, Haven AJ, Burnstock G (1986) Perivascular noradrenergic and peptide-containing nerves show different patterns of change during development and ageing in the guinea-pig. J Auton Nerv Syst 16:109-126.

Finch CE (1993) Ncuron atrophy during aging: programmed or sporadic. Trends Neurosci 16:104-110.

Fukuda J, Aosaki T, Keino K, Yamaguchi T (1991) Age-associated and cell-type specific changes in NGF requirement for neurite regeneration from trigeminal ganglion cells of the shrew (Suncus-Murinus). J Gerontol 46:B3-B16.

Gavazzi I, Cowen T (1993a) Axonal regeneration from rat sympathetic ganglia transplanted in oculo is not impaired by age. Exp Neurol 122: $57-64$.

Gavazzi I, Cowen T (1993b) NGF can induce a "young" pattern of innervation in transplanted old cerebral blood vessels. J Comp Neurol 334:489-496.

Gavazzi I, Andrews TJ, Thrasivoulou C, Cowen T (1992) Influence of target tissues on their innervation in old age: a transplantation study. Neuroreport 3:717-720.

Giacobini E (1988) The cholinergic system in ageing. In: The cholinergic synapse (Whittaker VP, ed). New York: Springer.

Goedert M, Fine A, Hunt SP, Ullrich A (1986) Nerve growth factor mRNA in peripheral and central rat tissues and in the human central nervous system: lesion effects in the rat brain and levels in Alzheimer's disease. Mol Brain Res 1:85-92.

Gulbenkian S, Wharton J, Polak JM (1987) The visualisation of cardiovascular innervation in the guinea pig using antiserum to protein gene product 9.5 (PGP9.5). J Auton Nerv Syst 18:235-247.

Hefti F, Mash DC (1989) Localization of nerve growth factor receptors in the normal human brain and in Alzheimer's disease. Neurobiol Ageing 10:75-87.

Hellweg R, Fischer W, Hock C, Gage FH, Bjorklund A, Thoenen $\mathrm{H}$ (1990) Nerve growth factor levels and choline acetyltransferase activity in the brain of aged rats with spatial memory impairments. Brain Res 537:123-130. 
Hempstead B, Martin-Zanca D, Kaplan DR, Parada LF, Chao MV (1991) High-affinity NGF binding requires coexpression of the trk proto-oncogene and the low affinity NGf receptor. Nature 350:678683

Holtzman DM, Li Y, Parada LF, Kinsman S, Chen CK, Valletta JS, Zhou J, Long JB, Mobley WC (1992) pl 40 trk mRNA marks NGF responsive forebrain neurons: evidence that trk gene expression is induced by NGF. Neuron 9:465-478.

Isaacson LG, Saffran BN, Crutcher KA (1990) Intracerebral NGF infusion induces hyperinnervation of cerebral blood vessels. Neurobiol Ageing 11:51-55.

Issacson IG, Saffran BN, Crutcher KA (1992) Nerve growth factorinduced sprouting of mature, uninjured sympathetic axons. J Comp Neurol 326:327-336.

Kedzierski W, Porter JC (1990) Quantitative study of tyrosine hydroxylase mRNA in catecholaminergic neurons and adrenals during development and aging. Mol Brain Res 7:45.

Klein R, Jing S, Nanduri V, Orourke E, Barbacid M (1991) The trk protooncogene encodes a receptor for nerve growth factor. Cell 65: 189-197.

Korsching S, Thoenen H (1983) Nerve growth factor in sympathetic ganglia and corresponding target organs of the rat: correlation with density of sympathetic innervation. Proc Natl Acad Sci USA 80 3513-3516.

Larkfors L, Ebendal T, Whittemore SR, Persson H, Hoffer B, Olson L (1987) Decreased level of nerve growth factor (NGF) and its messenger RNA in the aged rat brain. Mol Brain Res 3:55-60.

Levi-Montalcini R (1987) The nerve growth factor: 35 years later. Science 237:1154-1162.

Levi-Montalcini R, Booker B (1960) Destruction of the sympathetic ganglia in mammals by an antiserum to a nerve growth protein. Proc Natl Acad Sci IISA 46:384-391.

Levi-Montalcini R, Hamburger V (1951) Selective growth-stimulating effects of mouse sarcoma on the sensory and sympathetic nervous system of the chick embryo. J Exp Zool 116:321-361.

Lindsay RM, Lockett C, Sternberg J, Winter J (1989) Neuropeptide expression in cultures of adult sensory neurons: modulation of substance $P$ and calcitonin gene-related peptide levels by nerve growth factor. Neuroscience 33:53.

Lindvall O, Bjorklund A (1974) The glyoxylic acid fluorescence histochemical method: a detailed account of the methodology for the visualization of central catecholamine neurons. Histochemistry 39 : 92-127.

Miller FD, Mathew TC, Toma JG (1991) Regulation of nerve growth factor receptor gene expression by nerve growth factor in the developing peripheral nervous system. J Cell Biol 112:303-312.

Mione MC, Dhital KK, Amenta F, Burnstock B (1988) An increase in the expression of neuropeptidergic vasodilator, but not vasoconstrictor, cerebrovascular nerves in aging rats. Brain Res 460:103-113.

Montero CN, Hefti F (1989) Intraventricular nerve growth factor administration prevents lesion-induced loss of septal cholinergic neurons in aging rats. Neurobiol Ageing 10:739.

Perez-Polo JR, Werrbach-Perez K, Marchetti D, Morgan B, Taglialtela G, Ramacci MT, Angelucci L (1990) Nerve growth factor activity and aging in CNS. Int $\mathrm{J}$ Clin Pharmacol Res 10:15.

Purves D (1988) Body and brain, a trophic theory of neural connections. Cambridge, MA: Harvard UP.

Rossino P, Gavazzi I, Timpl R, Aumailley M, Abbadini M, Giancotti F, Silengo L, Marchisio PC, Tarone G (1990) Nerve growth factor induces increased expression of a laminin-binding integrin in rat pheochromocytoma PC12 cells. Exp Cell Res 189:100.

Ruit KG, Snider WD (1991) Administration or deprivation of nerve growth factor during development permanently alters neuronal geometry. J Comp Neurol 314:106-113.

Ruit KG, Osborne PA, Schmidt RE, Johnson EM, Snider WD (1990) Nerve growth factor regulates sympathetic ganglion cell morphology and survival in the adult mouse. J Neurosci 10:2412-2419.

Saffran BN, Crutcher KA (1990) NGF-induced remodeling of mature uninjured axon collaterals. Brain Res 525:11
Sanes JR (1989) Extracellular matrix molecules that influence neural development. Annu Rev Neurosci 12:491-516.

Sato A, Sato Y (1992) Regulation of regional cerebral blood flow by cholinergic fibers originating in the basal forebrain. Neurosci Res 14: 242-274.

Seiler M, Schwab ME (1984) Specific retrograde transport of neve growth factor (NGF) from ncocortcx to nuclcus basalis in the rat. Brain Res 300:33-39.

Selkoe DJ (1992) Aging brain and aging mind. Sci Am 267:96-103.

Shelton DL, Reichardt LF (1984) Expression of the $\beta$-nerve growth factor gene correlates with the density of sympathetic innervation in effector organs. Proc Natl Acad Sci USA 81:7951-7955.

Snider WD (1988) Nerve growth factor enhances dendritic arborization of sympathetic ganglion cells in developing mammals. J Neurosci 8:2628-2634.

Sofroniew MV, Galletly NP, Isacson O, Svendsen CN (1990) Survival of adult basal forebrain cholinergic neurons after loss of target neurons. Science 247:338-342.

Suhonen J, Koistinaho J, Hervonen A (1991) Histochemistry of sympathetic neurons allotransplanted from young and aged mice to the submandibular gland. Exp Neurol 112:104-111.

Tanaka M, Kanai H, Hirai S (1990) Effects of nerve growth factor on cultured adult dorsal root ganglion neurons evaluated by enzyme immunoassay for neurofilament protein. Age 13:57-60.

Thoenen $\mathrm{H}$ (1991) The changing scene of neurotrophic factors. Trends Neurosci 14:165-170.

Thoenen H, Angeletti PU, Levi-Montalcini R, Kettler R (1971) Selective induction by nerve growth factor of tyrosine hydroxylase and dopamine-B-hydroxylase in the rat superior cervical ganglia. Proc Natl Acad Sci USA 68:1598-1602.

Todd ME (1980) Development of adrenergic innervation in rat peripheral vessels: a fluorescence microscopic study. J Anat 131:121133.

Tuszynski MH, Sang H, Yoshida K, Gage FH (1991) Recombinant human nerve growth factor infusions prevent cholincrgic ncuronal degeneration in the adult primate brain. Ann Neurol 30:625-636.

Uchida Y, Tomonaga M (1985a) Nerve growth factor accelerates regenteration of cultured adult sympathetic ganglion cells. Age 8:19-20.

Uchida Y, Tomonaga M (1985b) Effects of nerve growth factor and heart cell conditioned medium on neurite regeneration of aged sympathetic neurons in culture. Brain Res 348:100-106.

Uchida Y, Tomonaga M (1987) Loss of nerve growth factor receptors in sympathetic ganglia from aged mice. Biochem Biophys Res Commun 146:797-801.

Varon S, Manthorpe M, Williams LR, Gage FH (1988) Neuronotrophic factors and their involvement in the adult central nervous system. In: Ageing and the brain (Terry RD, ed), pp 259-285. New York: Raven.

Webster GJM, Petch EWA, Cowen T (1991) Streptozotocin-induced diabetes in rats causes neuronal deficits in tyrosine hydroxylase and 5 -hydroxytryptamine specific to mesenteric perivascular sympathetic nerves and without loss of nerve fibers. Exp Neurol 113:53-62.

Wilson POG, Barber PC, Hamid QA, Power BF, Dhillon AP, Rode J, Day INM, Thompson RJ, Polak JM (1988) The immunolocalization of protein gene product 9.5 using rabbit polyclonal and mouse monoclonal antibodies. Br J Exp Pathol 69:91-104.

Wright LL, Luebke JI, Elshaar AE (1991) Target-specific subpopulations of rat superior cervical ganglion neurons. J Auton Nerv Syst 33:105-106.

Yankner BA, Shooter FM (1982) The biology and mechanism of action of nerve growth factor. Annu Rev Biochem 51:845-868.

Yoshida K, Gage FH (1992) Cooperative regulation of nerve growth factor synthesis and secretion in fibroblasts and astrocytes by fibroblast growth factor and other cytokines. Brain Res 569:14-25.

Zettler C, Head RJ, Rush RA (1991) Chronic nerve growth factor treatment of normotensive rats. Brain Res 538:251-262. 